\title{
Association Between Symptoms, Quality of Life, and Gastric Emptying in Dyspeptic Patients
}

\begin{abstract}
Fabien Wuestenberghs, ${ }^{1,2,3}$ Mathilde Juge, ${ }^{4}$ Chloé Melchior, ${ }^{3,4}$ Charlotte Desprez, ${ }^{2}$ Anne-Marie Leroi, ${ }^{5}$ and Guillaume Gourcerol ${ }^{2,3 *}$
${ }^{1}$ Department of Gastroenterology and Hepatology, CHU UCL Namur, Godinne University Hospital, UCLouvain, Yvoir, Belgium; ${ }^{2}$ Department of Physiology, Rouen University Hospital, Normandie University, Rouen, France; ${ }^{3}$ Nutrition, Gut and Brain Laboratory (INSERM UMR 1073), Institute for Biomedical Research and innovation, Rouen University, Normandie University, Rouen, France; ${ }^{4}$ Department of Gastroenterology, Rouen University Hospital, Normandie University, Rouen, France; and ${ }^{5}$ Department of Physiology, INSERM CIC-CRB 1404, Rouen University Hospital, INSERM Unit 1073, UNIROUEN, Normandie University, Rouen France
\end{abstract}

\section{Background/Aims}

Association between symptoms, quality of life and gastric emptying in dyspepsia is inconsistent in the literature. The aim of our study is to investigate if gastric emptying is associated with specific symptoms and quality of life in dyspeptic patients.

\section{Methods}

We reviewed retrospectively gastric emptying measured by ${ }^{13} \mathrm{C}$-labelled octanoate breath testing for more than 6 hours in 198 consecutive patients with dyspepsia complaints. Gastrointestinal symptoms were assessed using a 5-points Likert scale and by a symptomatic composite score, whereas quality of life was measured by the GIQLI.

\section{Results}

In our cohort, 90 patients (45\%) had a delayed gastric emptying (half emptying time above 166 minutes when assessed over 6-8 hours). There was no difference in symptoms or quality of life between patients with or without delayed gastric emptying. However, patients with severely delayed gastric emptying (half emptying time above 200 minutes) had increased postprandial fullness $(P=$ $0.012)$, abdominal pain $(P=0.026)$, bloating $(P=0.044)$, early satiety $(P=0.018)$, symptomatic composite score $(P=0.005)$, and a lower quality of life $(P=0.018)$. This association was no longer observed if the calculation of gastric emptying was limited to the first 4-hour samples.

\section{Conclusions}

There is no association between symptoms, quality of life and gastric emptying in an overall dyspeptic population. However, there is an association between symptoms, quality of life of delayed gastric emptying in the subgroup of patients with severely delayed gastric emptying. An 8-hour measurement of gastric emptying should be recommended.

(J Neurogastroenterol Motil 2019;25:534-543)

\section{Key Words}

Breath tests; Dyspepsia; Gastric emptying; Gastroparesis; Quality of life

Received: March 21, 2019 Revised: June 25, 2019 Accepted: July 20, 2019

(5) This is an Open Access article distributed under the terms of the Creative Commons Attribution Non-Commercial License (http://creativecommons. org/licenses/by-nc/4.0) which permits unrestricted non-commercial use, distribution, and reproduction in any medium, provided the original work is properly cited.

${ }^{*}$ Correspondence: Guillaume Gourcerol, MD, PhD

Nutrition, Gut and Brain Laboratory (INSERM UMR 1073), Institute for Biomedical Research, Department of Physiology, Rouen University Hospital-Charles Nicolle, 1 Rue de Germont, ROUEN Cedex 76031, France

Tel: +33-232-888-039, Fax: +33-232-888-425, E-mail: guillaume.gourcerol@chu-rouen.fr

Fabien Wuestenberghs and Mathilde Juge contributed equally to this work. 


\section{Introduction}

Functional dyspepsia (FD) and gastroparesis share similar symptoms, including nausea, vomiting, postprandial fullness, early satiety, and weight loss. Gastroparesis is defined by a delayed gastric emptying without mechanical obstruction of the stomach. ${ }^{1} \mathrm{FD}$ is associated with delayed gastric emptying in $40 \%$ of the cases. ${ }^{2}$ Therefore, the distinction between FD and gastroparesis is questioned. ${ }^{3-5}$

Methods to measure gastric emptying time which are mostly used in the literature are scintigraphy ${ }^{6}$ and breath testing. ${ }^{7}$ Measurements of gastric emptying by scintigraphy or ${ }^{13} \mathrm{C}$-labeled octanoic acid breath testing are known to be well correlated. ${ }^{8,9}$ Most of the studies published previously used a measurement over 4 hours since a consensus paper recommends gastric emptying scintigraphy to be performed over this period. ${ }^{10}$

There is no consensus to date in the medical literature about the relationship between symptoms and gastric emptying in patients with dyspeptic complaints. Indeed, among 14 studies $^{6,711-22}$ evaluating symptoms and quality of life in dyspeptic patients with gastric emptying evaluation, only six found a correlation with symptoms. ${ }^{11,13-15,18,21}$ Furthermore, even if abdominal pain was correlated to quality of life in gastroparesis, no association with gastric emptying delay was observed. ${ }^{23}$

With regards to the discrepancy in the literature, the aim of our study is to investigate whether gastric emptying is associated with symptoms and quality of life in a cohort of dyspeptic patients, with gastric emptying measured by 8 -hours ${ }^{13} \mathrm{C}$-labeled octanoic acid breath testing.

\section{Materials and Methods}

This monocentric study was performed at the Physiology Unit of Rouen University Hospital, in France. This is a retrospective analysis of prospectively acquired data. All patients had given written informed consent prior to the investigation, in accordance with the Declaration of Helsinki as revised in 2013. ${ }^{24}$ Approval was obtained from the French data protection authority in 2014 (Commission Nationale de l'Informatique et des Libertés, CNIL No. 817.917), in compliance with French legislation.

\section{Patients}

One hundred and ninety-eight consecutive patients referred for a gastric emptying breath test due to dyspeptic symptoms sugges- tive of gastroparesis lasting for at least 6 months were investigated from November 2013 to February 2016 in our tertiary care center. An organic upper gastrointestinal disorder was excluded by upper gastrointestinal endoscopy in all patients. Exclusion criteria were age below 18 years $(\mathrm{n}=2)$, history of gastric surgery, except fundoplication $(\mathrm{n}=9)$, pregnancy or breastfeeding $(\mathrm{n}=0)$, and patients in whom the breath test was prematurely interrupted before 6 hours $(\mathrm{n}=2)$. Medications known to alter gastric emptying (domperidone, metoclopramide, metopimazine, erythromycin, azithromycin and prucalopride) were asked to be stopped at least 1 week before the testing.

\section{Evaluation of Symptoms and Quality of Life}

Eight dyspeptic symptoms (postprandial fullness, abdominal pain, bloating, regurgitations, nausea, early satiety, belching, and vomiting) were collected prospectively using a 5-points Likert scale. These symptoms have been chosen since they are regularly found in the literature. ${ }^{18,25}$ Symptoms were graduated from 0 to 4 during the 15 days preceding the gastric emptying measurement, with 4 corresponding to their absence and 0 to extremely severe symptoms. We defined the absence of a symptom by a score greater or equal to 2 , and the presence of a symptom by a score inferior to 2 according to the 5-points Likert scale. A Total Symptom Score (TSS) was used to evaluate dyspepsia severity and was calculated by adding the eight individual symptoms. The score ranges from 0 to 32; the lower the score, the more severe the symptoms. The Gastrointestinal Quality of Life Index (GIQLI), a validated score in French, ${ }^{26}$ was used to measure quality of life. Anxiety and depression levels were also assessed, using the Hospital Anxiety Depression Scale (HADS) subscales. ${ }^{27} \mathrm{FD}$ criteria and irritable bowel syndrome (IBS) comorbidity were assessed using the Rome III criteria. ${ }^{28}$ Post-infectious origin to dyspeptic complaints was evaluated by asking for an episode of gastroenteritis one month before the onset of symptoms.'

\section{Gastric Emptying Assessment}

Gastric emptying measurement was performed by breath testing in patients starving for 12 hours before the investigation. The technique of carbon $13\left({ }^{13} \mathrm{C}\right)$-labelled octanoic acid breath testing, non-invasive and non-ionizing, has already been described elsewhere. ${ }^{29-31}$ All the patients ingested a $250-\mathrm{kcal}$ test meal between $8 \mathrm{AM}$ and $9 \mathrm{AM}^{29}$ The test meal was composed of $19 \%$ of proteins, $43 \%$ of carbohydrates and $38 \%$ of fat, in the form of $50 \mathrm{~g}$ of white bread, $17 \mathrm{~g}$ of butter and an egg in which $100 \mu \mathrm{L}(91 \mathrm{mg})$ of ${ }^{13} \mathrm{C}$-labeled octanoic acid (Euriso-Top, Saint Aubin, France) had been added to mark the solid phase of the test meal. Patients blowed 
into balloons and exhalations were collected immediately before eating the meal and every 15 minutes thereafter for up to 8 hours. The presence of ${ }^{13} \mathrm{C}$-labeled carbon dioxide was detected in breath samplings by infrared spectrometry (Kibion $\mathrm{GmbH}$, Bremen, Germany). ${ }^{32}$ Gastric half emptying time was calculated by regression analysis with the equation described by Ghoos et $\mathrm{al}^{29}$ in 1993, using the software InfraRed ISotope analyzer (IRIS; Wagner/Analysen Technik, Bremen, Germany). The equation, expressed as $\mathrm{T}_{1 / 2} \mathrm{~b}=$ $-1 / k^{*} \ln 1-2-1 / \beta$, takes into account the duration of the recording and the percentage of excretion of ${ }^{13} \mathrm{CO}_{2} \cdot{ }^{29,33}$ Gastric emptying was calculated for a single patient both on a 4-hour basis and for the whole duration of the study (between 6 and 8 hours).

\section{Study Description}

Half emptying time $\left(T_{1 / 2}\right)$, corresponding to the time required for $50 \%$ of the ingested meal to leave the stomach, was used to determine gastric emptying delay. For the first part of the study, we analyzed the results obtained over 6-8 hours using a cutoff for halfemptying time of 166 minutes. Indeed, the standard for delayed gastric emptying among healthy volunteers was defined by a $T_{1 / 2}$ $>166$ minutes for a duration of recording over more than 6 hours in the study of Bromer et al. ${ }^{34}$ For the second part of the study, we defined arbitrarily patients with severely delayed gastric emptying as having a $T_{1 / 2}$ superior to the 75 th percentile (200 minutes). Finally, we calculated the half-emptying time over the first 4 hours of recording to assess the impact of the length of measurement on the accuracy of the results.

\section{Statistical Methods}

All results were expressed by mean and standard deviation. Quantitative data were compared using an unpaired $t$ test, whereas qualitative variables were compared using Fisher's exact test, both with $95 \%$ confidence interval. Correlation between $T_{1 / 2}$ and quantitative variables was determined by the Pearson correlation coefficient. Lastly, the accuracy of the gastric emptying measurement in relation to the length of the breath test was analyzed by a Pearson correlation test, linear regression, and by a Bland-Altman plot. Data were analyzed using GraphPad Prism version 5.03 for windows (GraphPad Software Inc, San Diego, California, USA; available from URL: www.graphpad.com), except for multivariate analysis which was performed using SPSS software version 20.0. (released 2013; IBM Corp, Armonk, NY, USA). The covariates involved in the univariate and multivariate logistic regressions model included age, body mass index, diabetes mellitus, gender, GIQLI, heartburn, and IBS. Variables which were significantly associated with gastric half-emptying time in the univariate analysis were included in the multivariate logistic regression model and then analyzed by Forward Wald stepwise selection (entry probability 0.05 and removal probability 0.10 ), adjusting for the same covariates as used for the univariate model. Two-tailed $P$-value $<0.05$ was considered statistically significant.

\section{Results}

\section{Patient Characteristics and Their Correlation With Gastric Emptying}

Among the 198 analyzed patients, 149 patients (75.3\%) had a complete gastric emptying measurement of 8 hours, whereas 49 patients $(24.7 \%)$ had a measurement lasting 6 hours to 8 hours. There was no difference in quality of life in patients with or without diabetes mellitus (GIQLI scores of 78.4 and 80.8 respectively, $P=$ 0.470 ). Patients with IBS presented poorer quality of life (GIQLI scores of 71.9 points compared to 83.6 without overlap with IBS, $P$ $=0.002$ ). Clinical and demographic characteristics of the patients are presented in Table 1.

No correlation was found between patient's age $(r=-0.047, P$ $=0.515)$ or body mass index $(r=0.062, P=0.388)$ and gastric

Table 1. Patient Characteristics

\begin{tabular}{lc}
\hline \multicolumn{1}{c}{ Characteristics } & Patients $(\mathrm{N}=198)$ \\
\hline Age $(\mathrm{yr})$ & $49.6(18-83)$ \\
$\mathrm{BMI}\left(\mathrm{kg} / \mathrm{m}^{2}\right)$ & $25.1 \pm 6.1$ \\
Sex ratio male/female $(\%$ males) & $0.55(35.4)$ \\
$\mathrm{T}_{1 / 2}$ over $6-8 \mathrm{hr}(\mathrm{min})$ & $187.2 \pm 107.2$ \\
$\mathrm{~T}_{1 / 2}$ calculated over $4 \mathrm{hr}(\mathrm{min})$ & $169.7 \pm 78.1$ \\
Diabetes mellitus & $46(23.2)$ \\
Surgery for GERD or HH & $25(12.6)$ \\
Fulfilling FD criteria & $105(53.0)$ \\
Overlap with IBS & $57(28.8)$ \\
Episode of gastroenteritis before the onset of & $9(4.5)$ \\
symptoms & \\
TSS (score) & $16.9 \pm 6.3$ \\
GIQLI (score) & $80.2 \pm 24.6$ \\
HADS (score) & $15.7 \pm 6.9$ \\
HADS-A (subscore) & $9.4 \pm 3.9$ \\
HADS-D (subscore) & $6.3 \pm 4.1$ \\
\hline
\end{tabular}

BMI, body mass index; $T_{1 / 2}$, half emptying time; GERD, gastroesophageal reflux disease; $\mathrm{HH}$, hiatal hernia; $\mathrm{FD}$, functional dyspepsia; IBS, irritable bowel syndrome; TSS, Total Symptom Score; GIQLI, Gastrointestinal Quality of Life Index; HADS, Hospital Anxiety Depression Scale; HADS-A and HADS-D, HADS anxiety and depression subscales respectively. Data are presented as mean (range), $\mathrm{n}(\%)$, or mean $\pm \mathrm{SD}$. 
emptying. However, gastric emptying correlated with symptom severity assessed by TSS $(r=-0.215, P=0.002)$, quality of life assessed by the GIQLI $(r=-0.227, P=0.001)$ and anxiety and depression assessed by HADS $(r=0.206, P=0.004)$.

Among the overall population, 105 patients (53.0\%) fulfilled the Rome III criteria for FD. In the entire FD population, no correlation was found between quality of life assessed by the GIQLI and gastric emptying $(r=-0.041, P=0.680)$. Clinical and demographic characteristics of these patients are presented in supplementary material (Supplementary Tables 1, 2, 3, 6 and 7).

\section{Comparison Between Patients With a $\mathrm{T}_{1 / 2} \leq 166$ Minutes and > 166 Minutes}

One hundred and eight patients (54.5\%) had a $\mathrm{T}_{1 / 2} \leq 166 \mathrm{~min}$ utes and 90 patients $(45.5 \%)$ had a $T_{1 / 2}>166$ minutes. A history of type 1 or type 2 diabetes was more frequent in the group with delayed gastric emptying $(P=0.044)$. Other characteristics were similar in both groups and are presented in Table 2.

There was no difference between the 2 groups for all symptoms, as shown in Table 3.

Concerning quality of life, the GIQLI score was not correlated to the $\mathrm{T}_{1 / 2}(r=-0.027 ; P=0.778)$ among patients with a $\mathrm{T}_{1 / 2} \leq$ 166 minutes, whereas there was a correlation among patients with a $\mathrm{T}_{1 / 2}>166$ minutes $(r=-0.345 ; P<0.001)$. However, there was no difference in the GIQLI score between the groups with $T_{1 / 2} \leq$ 166 minutes and with $\mathrm{T}_{1 / 2}>166$ minutes (Table 2). Figures are shown in supplementary material (Supplementary Fig. 1).

\section{Comparison Between Patients With a $T_{1 / 2} \leq 200$ Minutes and $>200$ Minutes}

To explain the discrepancy between the correlation of the $T_{1 / 2}$ with the GIQLI score whereas the mean GIQLI values were not different in patients with $T_{1 / 2} \leq$ and $>$ to 166 minutes, we hypothesized that quality of life could be linked to the severity of the delayed gastric emptying. Characteristics of the population according to the presence or absence of severely delayed gastric emptying, using a $\mathrm{T}_{1 / 2}>200$ minutes, corresponding to the 75 th percentile, are presented in Table 4.

Table 3. Symptoms According to Gastric Half Emptying Time $\left(T_{1 / 2}\right)$ $\leq 166$ Minutes or $>166$ Minutes (Measured Over 6-8 Hours)

\begin{tabular}{lccr}
\hline \multicolumn{1}{c}{ Symptom } & $\begin{array}{c}\mathrm{T}_{1 / 2} \leq 166 \\
\min \\
(\mathrm{n}=108)\end{array}$ & $\begin{array}{c}\mathrm{T}_{1 / 2}>166 \\
\min \\
(\mathrm{n}=90)\end{array}$ & $P$-value \\
\hline Postprandial fullness & $56(1.6)$ & $46(1.5)$ & $>0.999$ \\
Abdominal pain & $38(1.9)$ & $39(1.9)$ & 0.246 \\
Bloating & $50(1.7)$ & $49(1.5)$ & 0.318 \\
Regurgitations & $33(2.3)$ & $31(2.2)$ & 0.647 \\
Nausea & $26(2.4)$ & $28(2.3)$ & 0.336 \\
Early satiety & $44(2.1)$ & $39(1.9)$ & 0.773 \\
Belching & $46(1.9)$ & $38(1.9)$ & $>0.999$ \\
Vomiting & $9(3.4)$ & $10(3.2)$ & 0.629 \\
TSS & $17.3 \pm 6.1$ & $16.5 \pm 6.6$ & 0.393 \\
\hline
\end{tabular}

TSS, Total Symptom Score.

Data are presented as n (mean score) or mean score $\pm \mathrm{SD}$.

Table 2. Characteristics of the Population According to Gastric Half Emptying Time $\left(T_{1 / 2}\right) \leq 166$ Minutes or $>166$ Minutes (Measured Over 6-8 Hours)

\begin{tabular}{|c|c|c|c|}
\hline Characteristics & $\mathrm{T}_{1 / 2} \leq 166 \min (\mathrm{n}=108)$ & $\mathrm{T}_{1 / 2}>166 \min (\mathrm{n}=90)$ & $P$-value \\
\hline Age (yr) & $50.0 \pm 16.1$ & $49.1 \pm 14.2$ & 0.666 \\
\hline $\mathrm{BMI}\left(\mathrm{kg} / \mathrm{m}^{2}\right)$ & $24.4 \pm 6.0$ & $25.9 \pm 6.1$ & 0.085 \\
\hline Sex ratio male/female ( $\%$ males) & $0.54(35.2)$ & $0.55(35.6)$ & $>0.999$ \\
\hline Diabetes mellitus & $19(17.6)$ & $27(30.0)$ & $0.044^{\mathrm{a}}$ \\
\hline Surgery for GERD or $\mathrm{HH}$ & $16(14.8)$ & $9(10)$ & 0.392 \\
\hline Overlap with IBS & $32(29.6)$ & $25(27.8)$ & 0.875 \\
\hline Episode of gastroenteritis before the onset of symptoms & $4(3.7)$ & $5(5.6)$ & 0.734 \\
\hline TSS (score) & $17.3 \pm 6.1$ & $16.5 \pm 6.6$ & 0.393 \\
\hline GIQLI (score) & $81.2 \pm 24.3$ & $79.1 \pm 24.8$ & 0.549 \\
\hline HADS (score) & $15.1 \pm 6.6$ & $16.5 \pm 7.2$ & 0.137 \\
\hline HADS-A (subscore) & $9.1 \pm 3.8$ & $9.7 \pm 4.0$ & 0.237 \\
\hline HADS-D (subscore) & $6.0 \pm 4.0$ & $6.8 \pm 4.2$ & 0.172 \\
\hline
\end{tabular}

${ }^{\mathrm{a}} P<0.05$.

BMI, body mass index; GERD, gastroesophageal reflux disease; HH, hiatal hernia; IBS, irritable bowel syndrome; TSS, Total Symptom Score; GIQLI, Gastrointestinal Quality of Life Index; HADS, Hospital Anxiety Depression Scale; HADS-A and HADS-D, HADS anxiety and depression subscales respectively.

Data are presented as mean $\pm \mathrm{SD}$ or $\mathrm{n}(\%)$. 
A

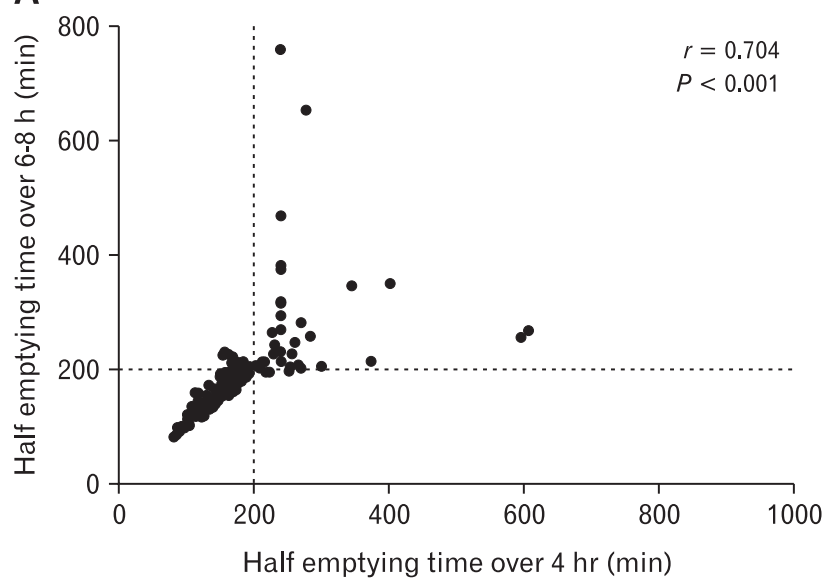

C

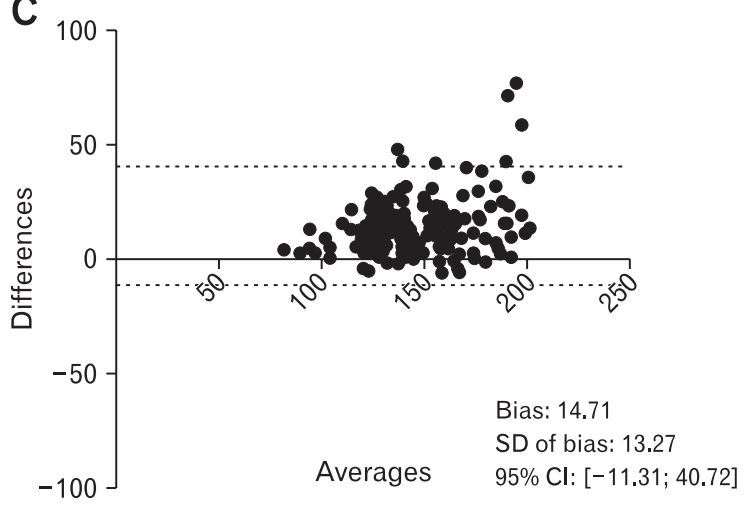

B

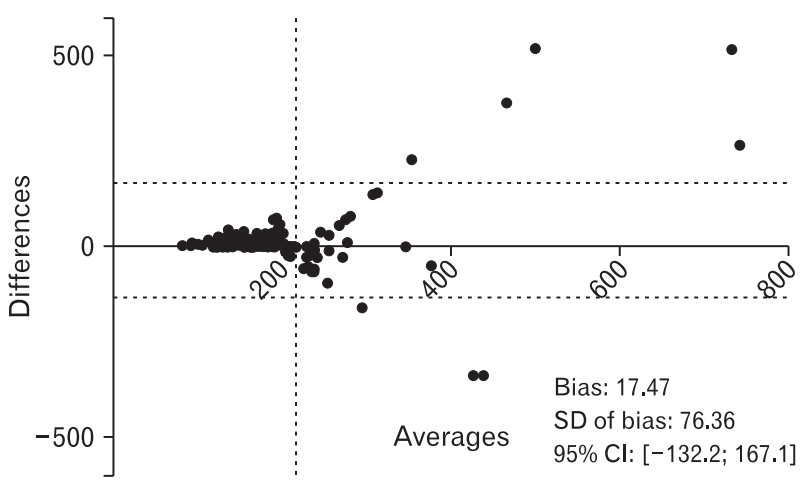

Figure. Correlation (A) and Bland-Altman plot between the calculations of the gastric half emptying time $\left(\mathrm{T}_{1 / 2}\right)$ over 4 hours and more than 6 hours for the overall population (B), for a $T_{1 / 2} \leq 200$ minutes $(C)$ and for a $T_{1 / 2}>200$ minutes (D).

There was a significant difference for symptoms of postprandial fullness $(P=0.012)$, abdominal pain $(P=0.026)$, bloating $(P=$ $0.044)$, early satiety $(P=0.018)$, and for the TSS $(\mathrm{P}<0.005)$. Results are shown in Table 5.

Concerning quality of life, the GIQLI score was not correlated to the $T_{1 / 2}$ among patients with a $T_{1 / 2} \leq 200$ minutes $(r=0.035$; $P=0.668$; Supplementary Fig. 2A). However, there was a correlation among patients with a $T_{1 / 2}>200$ minutes $(r=-0.344 ; P$ $=0.018$; Supplementary Fig. $2 \mathrm{~B}$ ). In the group with a $T_{1 / 2}<200$ minutes, the mean value of the GIQLI score was 82.5 in comparison to 73.0 in the group with a $T_{1 / 2}>200$ minutes $(P=0.020$; Supplementary Fig. 2C).

In univariate analysis, the only predictor variables of gastric half-emptying time $>200$ minutes were diabetes mellitus $(P=$ $0.005)$ and quality of life $(P=0.042)$. In multivariate analysis, the only predictor variables of gastric half-emptying time $>200 \mathrm{~min}-$ utes were also diabetes mellitus $(P=0.007)$ and quality of life $(P$
$=0.044)$. Results are shown in supplementary material (Supplementary Tables 4 and 5).

\section{Re-analysis of the Data Over 4 Hours Versus $>6$ Hours}

Finally, we compared patients with a $T_{1 / 2} \leq$ or $>200$ minutes after recalculating gastric emptying for all the patients with data of the first 4 hours only. We only observed a significant difference on abdominal pain $(P=0.033)$, which was more frequent when $T_{1 / 2}$ was $>200$ minutes, and the TSS, which was slightly decreased when $T_{1 / 2}$ was $>200$ minutes $(P=0.024)$. Other results are shown in supplementary material (Supplementary Table 8).

The GIQLI score was not correlated to the $T_{1 / 2}$ for the overall population anymore when using the calculation of $\mathrm{T}_{1 / 2}$ over 4 hours $(r=-0.128 ; P=0.072)$, neither in patients with a $\mathrm{T}_{1 / 2} \leq 200 \mathrm{~min}-$ utes $(r=0.012 ; P=0.882)$ nor in patients with a $T_{1 / 2}>200 \mathrm{~min}$ utes $(r=-0.072 ; P=0.653)$. Figures are shown in supplementary 
Table 4. Characteristics of the Population According to Gastric Half Emptying Time $\left(\mathrm{T}_{1 / 2}\right) \leq 200$ Minutes or $>200$ Minutes (Measured Over 6-8 Hours)

\begin{tabular}{|c|c|c|c|}
\hline Characteristics & $\begin{array}{c}\mathrm{T}_{1 / 2} \leq 200 \mathrm{~min} \\
(\mathrm{n}=151)\end{array}$ & $\begin{array}{c}\mathrm{T}_{1 / 2}>200 \mathrm{~min} \\
(\mathrm{n}=47)\end{array}$ & $P$-value \\
\hline Age (yr) & $49.7 \pm 16.0$ & $49.2 \pm 12.8$ & 0.824 \\
\hline $\operatorname{BMI}\left(\mathrm{kg} / \mathrm{m}^{2}\right)$ & $24.8 \pm 6.2$ & $25.8 \pm 5.6$ & 0.343 \\
\hline Sex ratio male/female ( $\%$ males) & $0.56(35.8)$ & $0.57(36.2)$ & 0.863 \\
\hline Diabetes mellitus & $27(17.9)$ & $19(40.4)$ & $0.003^{\mathrm{a}}$ \\
\hline Surgery for GERD or $\mathrm{HH}$ & $18(11.9)$ & $7(14.9)$ & 0.618 \\
\hline Overlap with IBS & $43(28.5)$ & $14(29.8)$ & 0.856 \\
\hline Episode of gastroenteritis before the onset of symptoms & $6(4.0)$ & $3(6.4)$ & 0.446 \\
\hline TSS (score) & $17.6 \pm 6.3$ & $14.7 \pm 6.0$ & $0.005^{\mathrm{a}}$ \\
\hline GIQLI (score) & $82.5 \pm 23.8$ & $73.0 \pm 25.5$ & $0.020^{\mathrm{a}}$ \\
\hline HADS (score) & $15.3 \pm 6.5$ & $17.2 \pm 7.8$ & 0.090 \\
\hline HADS-A (subscore) & $9.2 \pm 3.6$ & $10.1 \pm 4.6$ & 0.160 \\
\hline HADS-D (subscore) & $6.1 \pm 4.0$ & $7.1 \pm 4.3$ & 0.134 \\
\hline
\end{tabular}

${ }^{\mathrm{a}} P<0.05$.

BMI, body mass index; GERD, gastroesophageal reflux disease; HH, hiatal hernia; IBS, irritable bowel syndrome; TSS, Total Symptom Score; GIQLI, Gastrointestinal Quality of Life Index; HADS, Hospital Anxiety Depression Scale; HADS-A and HADS-D, HADS anxiety and depression subscales respectively.

Data are presented as mean $\pm \mathrm{SD}$ or $\mathrm{n}(\%)$.

Table 5. Symptoms According to Gastric Half Emptying Time $\left(\mathrm{T}_{1 / 2}\right)$ $\leq 200$ Minutes or $>200$ Minutes (Measured Over 6-8 Hours)

\begin{tabular}{|c|c|c|c|}
\hline Symptom & $\begin{array}{c}\mathrm{T}_{1 / 2} \leq 200 \mathrm{mir} \\
(\mathrm{n}=151)\end{array}$ & $\begin{array}{c}T_{1 / 2}>200 \mathrm{~min} \\
(\mathrm{n}=47)\end{array}$ & $P$-value \\
\hline Postprandial fullness & $70(1.7)$ & $32(1.2)$ & $0.012^{\mathrm{a}}$ \\
\hline Abdominal pain & $52(2.0)$ & $25(1.7)$ & $0.026^{\mathrm{a}}$ \\
\hline Bloating & $69(1.7)$ & $30(1.3)$ & $0.044^{\mathrm{a}}$ \\
\hline Regurgitations & $50(2.2)$ & $14(2.3)$ & 0.724 \\
\hline Nausea & $36(2.5)$ & $18(2.0)$ & 0.062 \\
\hline Early satiety & $56(2.1)$ & $27(1.6)$ & $0.018^{\mathrm{a}}$ \\
\hline Belching & $61(2.0)$ & $23(1.6)$ & 0.315 \\
\hline Vomiting & $14(3.4)$ & $5(3.1)$ & 0.780 \\
\hline TSS & $17.6 \pm 6.3$ & $14.7 \pm 6.0$ & $0.005^{\mathrm{a}}$ \\
\hline
\end{tabular}

${ }^{a} P<0.05$.

TSS, Total Symptom Score.

Data are presented as n (mean score) or mean score \pm SD.

material (Supplementary Fig. 3).

We found a strong correlation between the $T_{1 / 2}$ calculated over the first 4 hours and that established on the entire recording of more than 6 hours for the entire population $(r=0.704 ; P<0.001$; Figure A). However, a wider dispersion of results was noted for patients with a $T_{1 / 2}>200$ minutes after the Bland-Altman analysis (Figure B). Indeed, the concordance between measures of the $T_{1 / 2}$ over 4 hours and over more than 6 hours was less reliable for a $T_{1 / 2}$ $>200$ minutes, considering measurement over 6-8 hours as gold standard: bias between calculations over 4 hours and more than 6 hours was 14.7 with a standard deviation of 13.3 in patients with a
$\mathrm{T}_{1 / 2} \leq 200$ minutes (Figure C) while bias was 28.1 with a standard deviation of 167.0 in patients with a $T_{1 / 2}>200$ minutes (Figure D).

\section{Discussion}

In the literature, $30 \%$ to $40 \%$ of dyspeptic patients present delayed gastric emptying, diagnosed either by scintigraphy ${ }^{6}$ or by breath testing. ${ }^{7}$ We have found $45 \%$ of gastroparesis among dyspeptic patients in our cohort, which is slightly a greater percentage than what is described in the medical literature, maybe because we analyzed all dyspeptic patients referred for gastric emptying testing, and not only patients with FD according to the Rome criteria, but also because of normal values established by Bromer et al. ${ }^{34}$

In our study, gastric emptying broadly correlated to symptoms severity, quality of life and anxiety, and depression in an unselected population undergoing gastric emptying testing. There was no difference for symptoms and quality of life between groups with a $T_{1 / 2}$ $\leq 166$ or $>166$ minutes. However, for a $T_{1 / 2}>200$ minutes, there was a significant difference for postprandial fullness, abdominal pain, bloating, nausea and early satiety, and also for the TSS score and quality of life when the analysis was measured over more than 6 hours. Therefore, our study showed that the link between symptoms and gastric emptying exists for patients with severely delayed gastric emptying. To be clinically relevant, gastric emptying delay thresholds may be based on a selection of the more severe patients rather than on statistically abnormal values established among 
healthy volunteers. The exact norms defining severity of gastric emptying are thus still to be defined, both for ${ }^{13} \mathrm{C}$-labeled octanoic acid breath test and for gastric scintigraphy.

Diabetes mellitus was more frequent in groups with delayed or severely delayed gastric emptying and predicted the presence of severely delayed gastric emptying in multivariate analysis. However, there was no difference in quality of life in patients with or without diabetes mellitus in our study. On the contrary, IBS patients presented poorer quality of life but the presence of a diagnosis of IBS was not predictive of severely delayed gastric emptying in our cohort. Therefore, the alteration of quality of life in patients with severely delayed gastric emptying is not likely to be explained by diabetes mellitus or IBS, as shown in the supplementary material. Since the GIQLI score is a GI-specific quality of life questionnaire, it is possible that a more general score like SF-36 could have observed a difference in quality of life in patients with or without diabetes mellitus.

Discrepancies in the literature between symptoms and gastric emptying could be explained by the heterogeneity of the studies, with different evaluation methods used. Indeed, gastric emptying was measured by gastric scintigraphy or by ${ }^{13} \mathrm{C}$-labeled octanoic acid breath testing with various durations of recording, different test-meals and non-uniform symptoms collection. Most of the studies published previously used a measurement over 4 hours since a consensus paper recommends gastric emptying scintigraphy to be performed over this period. ${ }^{10}$ However, measurements of gastric emptying by scintigraphy or ${ }^{13} \mathrm{C}$-labeled octanoic acid breath testing are well correlated in the literature. ${ }^{8,9}$ Indeed, the choice of measurement technique did not seem to be implicated in the discrepancy between studies both scintigraphy and breath testing showing conflicting results. On the other hand, most of the studies published previously used a measurement over 4 hours. ${ }^{10}$ Our work suggests that the discrepancy found in the literature could partially be linked to the duration of the measurement of gastric emptying. Indeed, differences among symptoms correlated to the $T_{1 / 2}$ calculated over more than 6 hours but not if the calculation was limited to 4 hours in our study. This is probably due to a lack of accuracy of the measurement if limited to 4 hours once the $T_{1 / 2}$ exceeds 200 minutes. Measuring gastric emptying with ${ }^{13} \mathrm{C}$-labeled octanoic acid breath testing over 6 hours has been shown to be more reliable than over 4 hours. ${ }^{35}$ This has been confirmed in our study by a Bland-Altman analysis. The variability between measures over 4 hours and over more than 6 hours was 3 times superior when the $T_{1 / 2}$ threshold was set at 200 minutes in comparison to 166 minutes. A better estimation of the real emptying time could therefore be the explanation of the correlation found only in 8-hour measurements. Furthermore, our protocol could theoretically better select patients in whom accelerating gastric emptying could be a better target for symptom improvement. All these elements are in favor of a measurement of gastric emptying over 8 hours in current practice when using ${ }^{13} \mathrm{C}$ labeled octanoic acid breath testing. Similar results were found by Choi et al, ${ }^{36}$ with better correlation, when using breath testing compared to gastric scintigraphy, for measurements over 6 hours rather than 4 hours. However, implementing an 8-hour measurement in daily practice is patient-unfriendly and increases the cost of the procedure. Future studies should focus on identifying new algorithms to extrapolate the correct $T_{1 / 2}$ from shorter measurements.

Another possible explanation to the discrepancy relies on the test-meal. The study of Bromer et al, ${ }^{34}$ from which the norm of 166 minutes comes from, used a muffin of $350-\mathrm{kcal}^{37}$ in which $100 \mathrm{mg}$ of ${ }^{13} \mathrm{C}$-labeled octanoic acid have been added. Our choice to use a different test-meal from the one used in the study of Bromer et $\mathrm{al}^{34}$ is justified because it is a test-meal similar to the one used in the study by Ghoos et $\mathrm{al}^{29}$ from which our equation is based and because it is the most widely used in studies, even if these are limited to 4-hour measurements. ${ }^{14,38}$ Moreover, a high caloric load leads to a poor tolerance in many dyspeptic patients since it is known to delay gastric emptying. ${ }^{39}$ In our study, during the inclusion period, some patients have vomited their test-meal whereas it was only 250kcal.

On the other hand, the study of Bromer et $\mathrm{al}^{34}$ defined delayed gastric emptying by a $T_{1 / 2}>166$ minutes if the measurement was done over more than 6 hours. This norm was established upon only 9 healthy volunteers. This value necessitated to be reevaluated by complementary studies since it could overestimate the number of patients defined as suffering from gastroparesis. This could explain in part the fact that we did not find any difference for symptoms or quality of life between groups. In our study, the definition of the more severe patients was defined arbitrarily as the 75 th percentile.

Our work has several limitations. First, it is a monocentric study realized in a tertiary hospital, implying that patients could be more severe in comparison to secondary care. Nevertheless, most available studies in the literature have been realized in tertiary referral centers and this only factor cannot be incriminated to explain discrepancies between studies. Symptoms were collected prospectively, permitting to avoid biases due to heterogeneous measurements. Patients from which we could not calculate the $T_{1 / 2}$ have not been retained in the study. In the study, there was no significant difference concerning vomiting. Since some patients had vomited their test-meal, their exclusion could have led to a selection bias since 
excluding the more severe patients imply not reflecting anymore the dyspeptic population of origin. ${ }^{40}$ However, the number of those patients is very small (4 patients, $2 \%$ ). Finally, we did not realize any subgroup analysis according to treatments, especially as patients had to stop every treatment that could interact with the measurement of gastric emptying before the test.

Delayed gastric emptying could not explain all the different symptomatic profiles. Indeed, some studies have found other pathophysiological mechanisms like visceral hypersensitivity or gastric compliance disorders as triggers of dyspeptic symptoms. ${ }^{41,42}$ It is unlikely that gastric emptying itself could be the origin of all symptoms in gastroparesis. This is suggested in part by therapeutic trials. Indeed, the efficacy of gastric electrical stimulation on refractory nausea and vomiting is not linked to the acceleration in gastric emptying. ${ }^{43}$ Furthermore, the use of prokinetics ${ }^{12,44-47}$ or injections of intra-pyloric botulinum toxin ${ }^{38,48}$ did not improve symptoms in comparison to placebo, despite accelerating gastric emptying. Another study evaluating the efficacy of relamorelin, a selective ghrelin receptor agonist, that it accelerates gastric emptying in diabetic patients and reduces the frequency and severity of vomiting in comparison to placebo. ${ }^{49}$ However, the authors emphasized that there was no correlation between the acceleration of the gastric emptying and the improvement of symptoms. Up to now, there are only scarce data regarding correlation between gastric emptying acceleration and symptom improvement in gastroparesis. ${ }^{50}$

When performing subgroup analysis with all FD patients, we did not find any association between quality of life and halfemptying time. Showing an impact of the severity of gastric emptying delay in the overall dyspeptic population and not in FD patients suggests that the population of FD patients is too small to show a difference in our study. Therefore, these results suggest looking at the impact of severely delayed gastric emptying on symptoms and quality of life in a larger cohort of patients with FD.

In conclusion, our study demonstrates that there is no association between symptoms, quality of life, and gastric emptying measured with breath testing in an overall dyspeptic population. However, in patients with severely delayed gastric emptying, gastric emptying is associated with symptoms and quality of life, but this requires an 8-hour measurement. Indeed, a severely delayed gastric emptying can be diagnosed accurately only with an 8-hour measurement during ${ }^{13} \mathrm{C}$-labeled octanoic acid breath testing.

\section{Supplementary Materials}

Note: To access the supplementary tables and figures men- tioned in this article, visit the online version of Journal of Neurogastroenterology and Motility at http://www.jnmjournal.org/, and at https://doi.org/10.5056/jnm19060.

Acknowledgements: This article is dedicated to the memory of Professor Philippe Ducrotté, who passed away during the completion of the study. Philippe Ducrotté participated to the patient's recruitment but was unfortunately not involved in the manuscript drafting. The authors wish however to salute his contribution to this work. The authors will miss his mentoring, his leadership, and his friendship.

The authors are indebted to Alexis Deperrois, Gregory Mosni, and Christian Helluin (all from the Department of Physiology, Rouen University Hospital, Rouen, France) for technical help and data collection.

Financial support: This research received no specific grant from any funding agency in the public, commercial, or not-for-profit sectors. Fabien Wuestenberghs received support from the Fondation Mont-Godinne (Yvoir, Belgium) in 2017 and 2018.

\section{Conflicts of interest: None.}

Author contributions: Guillaume Gourcerol and Mathilde Juge designed the study and involved in acquisition of data; Guillaume Gourcerol, Mathilde Juge, and Fabien Wuestenberghs contributed to analysis and interpretation of data; and Guillaume Gourcerol, Mathilde Juge, and Fabien Wuestenberghs drafted the manuscript; and Guillaume Gourcerol, Mathilde Juge, Chloé Melchior, Charlotte Desprez, Anne-Marie Leroi, and Fabien Wuestenberghs provided critical revision of the manuscript for important intellectual content.

\section{References}

1. Parkman HP, Camilleri M, Farrugia G, et al. Gastroparesis and functional dyspepsia: excerpts from the AGA/ANMS meeting. Neurogastroenterol Motil 2010;22:113-133.

2. Quartero AO, de Wit NJ, Lodder AC, Numans ME, Smout AJ, Hoes AW. Disturbed solid-phase gastric emptying in functional dyspepsia: a meta-analysis. Dig Dis Sci 1998;43:2028-2033.

3. Lacy BE. Functional dyspepsia and gastroparesis: one disease or two? Am J Gastroenterol 2012;107:1615-1620.

4. Stanghellini V, Tack J. Gastroparesis: separate entity or just a part of dyspepsia? Gut 2014;63:1972-1978.

5. Kim BJ, Kuo B. Gastroparesis and functional dyspepsia: a blurring distinction of pathophysiology and treatment. J Neurogastroenterol Motil 2019;25:27-35. 
6. Talley NJ, Locke GR 3rd, Lahr BD, et al. Functional dyspepsia, delayed gastric emptying, and impaired quality of life. Gut 2006;55:933-939.

7. van Lelyveld N, Schipper M, Samsom M. Lack of relationship between chronic upper abdominal symptoms and gastric function in functional dyspepsia. Dig Dis Sci 2008;53:1223-1230.

8. Chew CG, Bartholomeusz FD, Bellon M, Chatterton BE. Simultaneous $13 \mathrm{C} / 14 \mathrm{C}$ dual isotope breath test measurement of gastric emptying of solid and liquid in normal subjects and patients: comparison with scintigraphy. Nucl Med Rev Cent East Eur 2003;6:29-33.

9. Choi MG, Camilleri M, Burton DD, Zinsmeister AR, Forstrom LA, Nair KS. [13C] octanoic acid breath test for gastric emptying of solids: accuracy, reproducibility, and comparison with scintigraphy. Gastroenterology 1997;112:1155-1162.

10. Abell TL, Camilleri M, Donohoe K, et al. Consensus recommendations for gastric emptying scintigraphy: a joint report of the American neurogastroenterology and motility society and the society of nuclear medicine. Am J Gastroenterol 2008;103:753-763.

11. Stanghellini V, Tosetti C, Paternico A, et al. Risk indicators of delayed gastric emptying of solids in patients with functional dyspepsia. Gastroenterology 1996;110:1036-1042.

12. Talley NJ, Verlinden M, Snape W, et al. Failure of a motilin receptor agonist (ABT-229) to relieve the symptoms of functional dyspepsia in patients with and without delayed gastric emptying: a randomized doubleblind placebo-controlled trial. Aliment Pharmacol Ther 2000;14:16531661.

13. Guo JP, Maurer AH, Fisher RS, Parkman HP. Extending gastric emptying scintigraphy from two to four hours detects more patients with gastroparesis. Dig Dis Sci 2001;46:24-29.

14. Sarnelli G, Caenepeel P, Geypens B, Janssens J, Tack J. Symptoms associated with impaired gastric emptying of solids and liquids in functional dyspepsia. Am J Gastroenterol 2003;98:783-788.

15. Cassilly DW, Wang YR, Friedenberg FK, Nelson DB, Maurer AH, Parkman HP. Symptoms of gastroparesis: use of the gastroparesis cardinal symptom index in symptomatic patients referred for gastric emptying scintigraphy. Digestion 2008;78:144-151.

16. Punkkinen J, Färkkilä M, Mätzke $\mathrm{S}$, et al. Upper abdominal symptoms in patients with type 1 diabetes: unrelated to impairment in gastric emptying caused by autonomic neuropathy. Diabet Med 2008;25:570-577.

17. Ardila-Hani A, Arabyan M, Waxman A, et al. Severity of dyspeptic symptoms correlates with delayed and early variables of gastric emptying. Dig Dis Sci 2013;58:478-487.

18. DiBaise JK, Patel N, Noelting J, Dueck AC, Roarke M, Crowell MD. The relationship among gastroparetic symptoms, quality of life, and gastric emptying in patients referred for gastric emptying testing. Neurogastroenterol Motil 2016;28:234-242.

19. Guo WJ, Yao SK, Zhang YL, Yan J, Yin LJ, Li HL. Relationship between symptoms and gastric emptying of solids in functional dyspepsia. J Int Med Res 2012;40:1725-1734.

20. Talley NJ, Shuter B, McCrudden G, Jones M, Hoschl R, Piper DW. Lack of association between gastric emptying of solids and symptoms in nonulcer dyspepsia. J Clin Gastroenterol 1989;11:625-630.

21. Tseng AS, Crowell MD, DiBaise JK. Clinical utility of gastric emptying scintigraphy: patient and physician perspectives. Neurogastroenterol Motil 2018;30:e13279.

22. Asano H, Tomita T, Nakamura K, et al. Prevalence of gastric motility disorders in patients with functional dyspepsia. J Neurogastroenterol Motil 2017;23:392-399.

23. Cherian D, Sachdeva P, Fisher RS, Parkman HP. Abdominal pain is a frequent symptom of gastroparesis. Clin Gastroenterol Hepatol 2010;8:676-681.

24. World Medical Association. World medical association declaration of helsinki: ethical principles for medical research involving human subjects. JAMA 2013;310:2191-2194.

25. Revicki DA, Rentz AM, Dubois D, et al. Gastroparesis cardinal symptom index (GCSI): development and validation of a patient reported assessment of severity of gastroparesis symptoms. Qual Life Res 2004;13:833-844.

26. Slim K, Bousquet J, Kwiatkowski F, Lescure G, Pezet D, Chipponi J. [First validation of the French version of the gastrointestinal quality of life index (GIQLI)]. Gastroenterol Clin Biol 1999;23:25-31.[French]

27. Zigmond AS, Snaith RP. The hospital anxiety and depression scale. Acta Psychiatr Scand 1983;67:361-370.

28. Longstreth GF, Thompson WG, Chey WD, Houghton LA, Mearin F, Spiller RC. Functional bowel disorders. Gastroenterology 2006;130:1480-1491.

29. Ghoos YF, Maes BD, Geypens BJ, et al. Measurement of gastric emptying rate of solids by means of a carbon-labeled octanoic acid breath test. Gastroenterology 1993;104:1640-1647.

30. Gourcerol G, Benanni Y, Boueyre E, Leroi AM, Ducrotte P. Influence of gastric emptying on gastro-esophageal reflux: a combined $\mathrm{pH}$ impedance study. Neurogastroenterol Motil 2013;25:800-e634.

31. Gourcerol G, Tissier F, Melchior C, et al. Impaired fasting pyloric compliance in gastroparesis and the therapeutic response to pyloric dilatation. Aliment Pharmacol Ther 2015;41:360-367.

32. Mion F, Ecochard R, Guitton J, Ponchon T. ${ }^{13} \mathrm{CO}_{2}$ breath tests: comparison of isotope ratio mass spectrometry and non-dispersive infrared spectrometry results. Gastroenterol Clin Biol 2001;25:375-379.

33. Delbende B, Perri F, Couturier O, et al. ${ }^{13} \mathrm{C}$-octanoic acid breath test for gastric emptying measurement. Eur J Gastroenterol Hepatol 2000;12:8591.

34. Bromer MQ, Kantor SB, Wagner DA, Knight LC, Maurer AH, Parkman HP. Simultaneous measurement of gastric emptying with a simple muffin meal using $\left[{ }^{13} \mathrm{C}\right]$ octanoate breath test and scintigraphy in normal subjects and patients with dyspeptic symptoms. Dig Dis Sci 2002; 47:1657-1663.

35. Clegg ME, Shafat A. Procedures in the ${ }^{13} \mathrm{C}$ octanoic acid breath test for measurement of gastric emptying: analysis using bland-altman methods. Scand J Gastroenterol 2010;45:852-861.

36. Choi MG, Camilleri M, Burton DD, Zinsmeister AR, Forstrom LA, Nair KS. Reproducibility and simplification of ${ }^{13} \mathrm{C}$-octanoic acid breath test for gastric emptying of solids. Am J Gastroenterol 1998;93:92-98.

37. Perri F, Bellini M, Portincasa P, et al. ${ }^{13} \mathrm{C}$-octanoic acid breath test (OBT) with a new test meal (EXPIROGer ${ }^{\circledR}$ ): toward standardization for testing gastric emptying of solids. Dig Liver Dis 2010;42:549-553. 
38. Arts J, Holvoet L, Caenepeel P, et al. Clinical trial: a randomizedcontrolled crossover study of intrapyloric injection of botulinum toxin in gastroparesis. Aliment Pharmacol Ther 2007;26:1251-1258.

39. Marciani L, Gowland PA, Spiller RC, et al. Effect of meal viscosity and nutrients on satiety, intragastric dilution, and emptying assessed by MRI. Am J Physiol Gastrointest Liver Physiol 2001;280:G1227-G1233.

40. Parkman HP, Hallinan EK, Hasler WL, et al. Nausea and vomiting in gastroparesis: similarities and differences in idiopathic and diabetic gastroparesis. Neurogastroenterol Motil 2016;28:1902-1914.

41. Bisschops R, Karamanolis G, Arts J, et al. Relationship between symptoms and ingestion of a meal in functional dyspepsia. Gut 2008;57:14951503.

42. Kumar A, Attaluri A, Hashmi S, Schulze KS, Rao SS. Visceral hypersensitivity and impaired accommodation in refractory diabetic gastroparesis. Neurogastroenterol Motil 2008;20:635-642.

43. Gourcerol G, Leblanc I, Leroi AM, Denis P, Ducrotte P. Gastric electrical stimulation in medically refractory nausea and vomiting. Eur J Gastroenterol Hepatol 2007;19:29-35.

44. Talley NJ, Verlinden M, Geenen DJ, et al. Effects of a motilin receptor agonist (ABT-229) on upper gastrointestinal symptoms in type 1 diabetes mellitus: a randomised, double blind, placebo controlled trial. Gut
2001;49:395-401

45. Janssen P, Harris MS, Jones M, et al. The relation between symptom improvement and gastric emptying in the treatment of diabetic and idiopathic gastroparesis. Am J Gastroenterol 2013;108:1382-1391.

46. Tack J, Rotondo A, Meulemans A, Thielemans L, Cools M. Randomized clinical trial: a controlled pilot trial of the $5-\mathrm{HT}_{4}$ receptor agonist revexepride in patients with symptoms suggestive of gastroparesis. Neurogastroenterol Motil 2016;28:487-497.

47. Sugumar A, Singh A, Pasricha PJ. A systematic review of the efficacy of domperidone for the treatment of diabetic gastroparesis. Clin Gastroenterol Hepatol 2008;6:726-733.

48. Friedenberg FK, Palit A, Parkman HP, Hanlon A, Nelson DB. Botulinum toxin A for the treatment of delayed gastric emptying. Am J Gastroenterol 2008;103:416-423.

49. Lembo A, Camilleri M, McCallum R, et al. Relamorelin reduces vomiting frequency and severity and accelerates gastric emptying in adults with diabetic gastroparesis. Gastroenterology 2016;151:87-96, e6.

50. Malik Z, Kataria R, Modayil R, et al. Gastric per oral endoscopic myotomy (G-POEM) for the treatment of refractory gastroparesis: early experience. Dig Dis Sci 2018;63:2405-2412. 